\title{
MELT-SPINNING AND SEMI-SOLID PROCESSING OF
}

\section{BAINITIC STEEL}

\author{
L. Rogal ${ }^{1 \mathrm{a}}$, W Solano-Alvarez ${ }^{2}$, H.K.D.H. Bhadeshia ${ }^{2}$ \\ ${ }^{1}$ Institute of Metallurgy and Materials Science of the Polish Academy of Sciences, \\ 25 Reymonta St., 30-059 Krakow, Poland \\ ${ }^{2}$ Department of Materials Science and Metallurgy, University of Cambridge, UK
}

Corresponding author: Ł. Rogal, e-mail: 1.rogal@imim.pl, phone+48 122952801, fax +48 122952804.

\begin{abstract}
.
A steel with a chemical composition meant to form nanostructured bainite following appropriate heat treatment, was cooled rapidly from the liquid phase $\left(1550{ }^{\circ} \mathrm{C}\right)$ using melt spinning and modified injection-suction methods, as well as from a semi-solid temperature $\left(1430{ }^{\circ} \mathrm{C}\right.$ ) through thixoforming. The hardness of the as-cast melt-spun ribbons was $\sim 900 \mathrm{HV}$ due to a fine martensite-austenite mixture surrounded by-3-dimensional skeleton-like primary carbides of length scale $0.2-0.3 \mu \mathrm{m}$. The suction-injection cast method led to a similar structure but less hard $(780 \mathrm{HV})$ due to a lower cooling rate. The thixoformed material showed unmelted globular fine grains and a eutectic mixture formed directly from the liquid phase. The variety of processed steel samples were tempered and their microstructures examined.
\end{abstract}

\section{Introduction}

Unconventional methods of production applied to conventional materials can occasionally lead to an improvement of their mechanical properties [1-3] with the possibility of new industrial products or processes [4, 5]. After all, the conditions of crystallization during solidification have a direct impact on grain morphology, shrinkage cavity, and the distribution of secondary and tertiary phases [6]. The rapid solidification in particular increases structural and chemical homogeneity, with solute trapping during transformation that avoids the problems of solute partitioning [7]. Conventional solidification can leave regions containing 
macro and micro segregation of elements and numerous structural defects [8], although subsequent processing can resolve all of these issues. The present work is therefore driven purely by curiosity rather than any belief that these unusual processes might lead to breakthroughs in technology. Furthermore, the work focuses on a steel that is conventionally used to produce nanostructured bainite $[9,10]$, adding to the intrigue. The work may in addition reveal the role of parameters, such as the cooling rate, for alternative processing methods, as evidenced by a recent study on the feasibility of thixoforming nanostructured bainitc steels [25].

\section{Experimental procedure}

\subsection{Microstructure and hardness analysis}

The steel (designated SB steel) was supplied as a bar of $300 \mathrm{~mm}$ in diameter. Its composition, measured after homogenisation at $1200{ }^{\circ} \mathrm{C}$ for 2 days, was $0.74 \mathrm{C}-1.64 \mathrm{Si}-1.82 \mathrm{Mn}-1 \mathrm{Ni}-$ 0.36Mo-0.21Cr-0.047Al wt $\%$, determined using optical emission spectrometry. The metallography was carried out using a Leica DM IRM microscope and associated image analysis software. A DuPont 910 instrument was used to measure thermal effects during heating in the solid state. A Netzsch 404F1 differential scanning calorimeter was used to determine the solidus-liquidus range and the amount of the liquid phase as a function of temperature. Whole calorimetric studies have been conducted at the heating rate of $20{ }^{\circ} \mathrm{C} / \mathrm{min}$ in an argon atmosphere. Before X-ray investigations, the samples were prepared by grinding with silicon carbide papers (1200, 2500, and 4000), polishing with $1 \mu \mathrm{m}$ diamond paste, etching in nital (2\%), and re-polishing with $0.25 \mu \mathrm{m}$ paste in order to minimise surface deformation effects. All samples were tested in a Bruker D8 Advance diffractometer equipped with a position sensitive detector using a $10 \mathrm{~mm}$ slit, without $\mathrm{Ni}$ filter, and with $\mathrm{Cu} \mathrm{K} \alpha$ radiation. The samples were run from $30-135^{\circ}$ with a $5 \mathrm{~s}$ dwell time, $0.02^{\circ}$ step size, energy levels of $210-226 \mathrm{mV}$, and the rotation speed of $30 \mathrm{rad}^{-1}$. The diffraction data were analysed using Rietveld refinement $[11,26]$ in HighScore plus [27] by fitting austenite to three nonoverlapping austenite peaks: 002, 022 and 113. The resulting maximum and minimum estimates of the austenite lattice parameter were then used to calculate its carbon concentration as in [12]. Since the carbon content is inherited by the martensite, its maximum and minimum values of tetragonality were obtained according to [13]. The lattice parameters $\left(\mathrm{a}_{\gamma}, \mathrm{a}_{\alpha}\right.$, and $\mathrm{c}_{\alpha}$ ) were used to fit martensite, retained austenite, and bainitic ferrite to the whole spectrum. The microanalysis was performed on a scanning electron microscope, FEI SEM 
XL30 equipped with an energy-dispersive X-ray spectrometer EDAX GEMINI 4000. The transmission electron microscopy was performed on a Philips CM20 and Tecnai G2 F20 instruments, with samples prepared by electropolishing using a $20 \%$ vol. - HClO4 and 80 \%vol. $\mathrm{CH}_{3} \mathrm{OH}$ mixtures at subzero temperatures. Vickers hardness tests carried out using a Zwick/ZHU 250 (HV5) and CSM Instruments micro-hardness tester.

\subsection{Rapid quenching}

Melt spinning enables a solidification cooling rate of up to $10^{6}{ }^{\circ} \mathrm{C} / \mathrm{s}$. The experiments were performed in a helium atmosphere and a linear copper wheel rate of $25 \mathrm{~m} / \mathrm{s}$. The steel was heated in an inductive furnace inside a boron nitride crucible, which contained a $0.7 \mathrm{~mm}$ hole at the bottom. The ejection of liquid steel on the rotating wheel was performed at $1450{ }^{\circ} \mathrm{C}$ and under a pressure of 2.5 bar. The ribbons produced were several centimetres in length and 40$80 \mu \mathrm{m}$ thick, Fig. 1a. An alternative method, which enabled to obtain a highly rapid quenched material was the suction process $[14,15]$, in which the molten steel $(50 \mathrm{~g})$ was cast into a copper die (cavity shape $20 \times 20 \times 3 \mathrm{~mm}$ ) by a suction force resulting from the difference between the pressure in the crucible (over-pressure, 0.5 bar) and the die (under-pressure, $5.1 \times 10^{-1}$ bar). Finally, the plates presented in Fig. $1 \mathrm{~b}$ were obtained at cooling rates of about $5 \times 10^{2}{ }^{\circ} \mathrm{C} / \mathrm{s}$. The rapid cooling from the semi-solid state was applied as the last method. A sample with the diameter of $30 \mathrm{~mm}$ and a height of $30 \mathrm{~mm}$ was heated at a rate of 150 ${ }^{\circ} \mathrm{C} /$ min to $1430{ }^{\circ} \mathrm{C}$ to get about $30 \%$ liquid according to the DSC curve (Fig. 2, point A on dashed line), followed by thixioforming into a steel die at ambient temperature and pressure. The average cooling rate of the obtained thixo-formed material (Fig. 1c) with rectungular shape $(30 \times 50 \times 10 \mathrm{~mm})$ was about $150^{\circ} \mathrm{C} / \mathrm{s}$.

\section{Results and discussion}

\subsection{Melting temperature and solidus-liquidus range}

Differential scanning calorimetry was used to determine the approximate solidus-liquidus range, Fig. 2. The steel started melting at $1350{ }^{\circ} \mathrm{C}$, and was completely liquid at $1476{ }^{\circ} \mathrm{C}$. The smooth onset of the melting heat-flow curve during heating is likely to be due to chemical homogeneity in the sample. The liquidus temperature during cooling was about $8{ }^{\circ} \mathrm{C}$ lower, as expected in the absence of heating or cooling rates that are inconsistent with the establishment of equilibrium. The solidification process had two stages: the first, between $1468-1408^{\circ} \mathrm{C}$ was due to the exothermic formation of austenite from the liquid. The second step, over the range $1408-1345{ }^{\circ} \mathrm{C}$ was due to the eutectic reaction in which the remaining liquid decomposed into 
a mixture of $\mathrm{M}_{3} \mathrm{C}$ and $\gamma$-Fe, where ' $\mathrm{M}$ ' refers to metal atoms. The solidus temperature was determined as $\sim 1345{ }^{\circ} \mathrm{C}$. The liquid fraction is plotted in Fig. 2 as a dashed line with the point A at $1430^{\circ} \mathrm{C}$ corresponding to the thixoforming temperature where the liquid content is $30 \%$.

\subsection{Melt spun ribbons}

Rapid solidification began with the melt superheated to $1550{ }^{\circ} \mathrm{C}$, which exceeds the measured liquidus temperature by $74^{\circ} \mathrm{C}$, followed by melt spinning to ribbons $5 \mathrm{~mm}$ wide and $40-80 \mu \mathrm{m}$ thick. It was established in a previous study [16], that the rates of cooling during meltspinning are in the range of $4 \times 10^{3}-5 \times 10^{6}{ }^{\circ} \mathrm{C} / \mathrm{s}$. Fig. 3 shows the cross-section of a ribbon. The central and bottom regions show relatively coarse columnar and dendritic grains, consistent with a lower cooling rate relative to the surface. The atomic number contrast in Fig. 3b, c indicates that the light regions correspond to carbides present in the areas between the matrix dendrites. In the high cooling-rate region near the contact surface, the amount of these secondary phases was $6 \pm 0.5 \mathrm{vol} \%$, while in the central part of the ribbon the amount of $9 \pm 0.7$ vol\% was recorded. This again is consistent with the expected cooling rate differences as a function of depth below the contact surface. Fig. 4 shows a TEM micrograph of the flat area of ribbons, whose surface was in contact with the $\mathrm{Cu}$-wheel (top area in Fig. 3a). The carbide network clearly forms a network around the globular grains. Similar observations have been reported on other alloy systems that contain large carbon concentrations [3, 17]. Fig. 5a shows the network of cementite layers with an apparent thickness of about $20 \mathrm{~nm}$ surrounding martensitic regions of about $0.4 \mu \mathrm{m}$ in size. The martensite is twinned (Fig. 6), consistent with its high carbon concentration.

X-ray analysis of the melt-spun ribbons, plate, and thixo-formed samples are shown in Fig. 7. Differences in peak positions between $\alpha$-Fe and $\gamma$-Fe, which are related to carbon concentration, are clearly visible. The detailed analysis of the melt spun ribbon spectrum using the Rietveld refinement method confirmed the presence of $74 \pm 1$ vol\% martensite and $26 \pm 1$ vol $\%$ austenite. However, the diffracted intensity from $\mathrm{M}_{3} \mathrm{C}$ carbides, which occupy only about 2 vol.\% of the microstructure, could not be clearly established given the error in the major phase determinations of \pm 1 vol\%.

\subsection{Microstructure of steel plate produced by suction casting}

The application of the suction casting method enables the fabrication of bulk materials, but the cooling rates $\left(300-500{ }^{\circ} \mathrm{C} / \mathrm{s}\right)$ involved are lower than during melt spinning. Rectangular plates $3 \mathrm{~mm}$ thick plates with $20 \times 30 \mathrm{~mm}$ sections were fabricated. The reduced cooling rate 
led to large changes in the microstructure. The solidification microstructure revealed several micrometres long dendrites together with a coarse, continuous, carbide network, homogeneously distributed over the whole plate (Fig. 8a); Fig. 8b shows a cross-section of a columnar grain area containing a martensite and austenite mixture surrounded by carbides. Typical casting defects, such as porosity (marked with arrows) or segregation occurred in some carbide-eutectic areas, which presumably are the last to solidify. Fig. 8b confirms the presence of martensite and large $\mathrm{M}_{3} \mathrm{C}$ cementite particles up to $0.5 \mu \mathrm{m}$ thick and 2-3 $\mu \mathrm{m}$ long. The X-ray analysis (Fig. 7c) indicated $70 \pm 1 \%$ of martensite and ferrite and $30 \pm 1 \%$ of retained austenite. The combination of untempered martensite and cementite led to a hardness of 654 $\mathrm{HV}$, similar to that of high-speed tool steels rapidly cooled from the liquid phase [3].

\subsection{Microstructure of thixo-formed steel}

The microstructure of samples thixo-formed at $1430{ }^{\circ} \mathrm{C}$, where liquid occupies $30 \%$ of the material, following cooling in a cold steel die, is presented in Fig. 9. Unmelted, primary globular grains about $120 \mu \mathrm{m}$ in size are finer grains of about $20 \mu \mathrm{m}$ in size, with a eutectic mixture in between, formed directly from the liquid phase. Fine martensite is visible in the centre of the globular grains (Fig. 9a) and X-ray diffraction (Fig. 9b) indicated about $81 \pm 1 \%$ of $\alpha-\mathrm{Fe}$ and $19 \pm 1 \%$ of austenite. The observed morphologies are consistent with semi-solid slurry flows under the action of shear stresses, causing the mixture of components in the liquid phase, that crystallises into a eutectic mixture and small grains. The hardness of the globular grains was $610 \mathrm{HV}$, whereas that of the small secondary grains was $420 \mathrm{HV}$.

Fig. 10 shows that there are microscopic cracks in the coarse martensite plates of the thixoformed samples; this is entirely expected from studies that show that quench cracks do not occur in fine martensite because as in fibre composites, the plates must be large enough to permit stress transfer across the interface [18]. The energy dispersive X-ray analysis scan (Fig. 10) shows the level of chemical segregation between the globular grains, although it is noted that the analysis of carbon is indicative rather than quantitatively accurate.

The chemical composition of the eutectic mixture (points 2, 3, Fig. 10a) are also presented in Table 1, reveal excess concentrations of Mo, Mn and S, possibly due to the presence of MnS. In the case of silicon, it is visible in the line scan profile (Fig. 10b) that just before the grain boundary its content increases and then suddenly decreases at the eutectic mixture area, presumably because of its rejection by the carbides in the eutectic. The most important role in the segregation effect is played by carbon, whose high content near the grain boundary may stabilise austenite and allow carbides to form. 


\subsection{Microstructural stability as a function of production method}

Differential scanning calorimetric experiments were conducted on the samples directly after rapid-solidification and semi-solid processing, as well as on the reference sample previously subjected to typical heat treatment which led to the formation of nanostructured bainite (1000 ${ }^{\circ} \mathrm{C}, 15 \mathrm{~min}$ followed by $240{ }^{\circ} \mathrm{C}, 20 \mathrm{~h}$ ) [19], Figs. 11,12 and Table 2 . The exothermic effects marked 'I' suggest that precipitation during continuous heating over the range $112-216{ }^{\circ} \mathrm{C}$, is probably associated with the tempering of the martensite, consistent with the change in hardness relative to the as-cast state (Fig. 12) following this low temperature-range tempering. The wider exothermic effect over the range $195-405{ }^{\circ} \mathrm{C}$ is probably related to the decomposition of retained austenite [21]. The increased hardness of ribbons after tempering at $350{ }^{\circ} \mathrm{C} / 2 \mathrm{~h}$ resulted mainly from the transformation of austenite into fine supersaturated ferrite/martensite (during cooling from the tempering temperature), due to the decrease of the $\gamma$-Fe content by about 3 vol.\% in relation to the state after direct casting. Fig. 13 presents TEM micrographs of the ribbons after tempering at $350{ }^{\circ} \mathrm{C} / 2 \mathrm{~h}$. It shows plates of martensite/ferrite with thickness of 5-25 nm, as well as dark contrast points (all along right side) probably from numerous defects. The high resolution transmission electron micrograph (HRTEM, taken from the area in Fig. 13) with inserted Fast Fourier Transform (FFT) is shown in Fig.14a. From the lattice distances and their mutual angles measured using FFT, the ferrite/martensite [1-11] zone axis orientation was identified, which fitted well to the simulation of the reciprocal lattice section at that orientation. Additional less visible reflections (marked with arrows) probably from $\mathrm{M}_{3} \mathrm{C}$ or transitional carbides [22] (lattice distance $0.26 \mathrm{~nm}$ and angle $36^{\circ}$ ) are visible. The inverse FFT obtained using Digital Micrograph software by applying masks near reflections in the FFT showed much better contrast as can be seen in Fig. 14b. High density of defects (visible as changes in contrast) e.g. edge or complex dislocations are well visible in the Fourier filtered part of the image. In addition, the usage of masks for chosen reflections in the inverse FFT allowed to obtain the Fourier filtered image in certain crystallographic directions (Fig. 15) in which numerous edge dislocations are visible. Defects as well as secondary carbides could be responsible for the hardening effect of ribbons. 
The X-ray diffraction analysis (Table 3) for three different types of samples (plate, thixoformed, and ribbons) all tempered at $350{ }^{\circ} \mathrm{C}$ for $2 \mathrm{~h}$, have the same phases with slightly different volume fractions. However, the most likely reasons of differences in hardness (mainly of ribbons) are size and morphology of phases formed after tempering, which is directly related with the thermal history of the material. In any case, the results evidence that the most adequate tempering temperature is likely to be $350{ }^{\circ} \mathrm{C}$. In order to determine the influence of the tempering time on the hardening effect in the SB steel ribbons, tempering at $300{ }^{\circ} \mathrm{C}$ for $1,2,3$, and $4 \mathrm{~h}$ was carried out. The results presented in Fig. 16 show that the hardness initially decreased from $963 \mathrm{HV}$ (state directly after casting) to $700 \mathrm{HV}$ and $629 \mathrm{HV}$ after 1 and $2 \mathrm{~h}$ of tempering, respectively. As it was mentioned before, after direct casting there was martensite, retained austenite, and a small amount of $\mathrm{M}_{3} \mathrm{C}$ carbide skeleton (Table 4), but upon tempering the highly metastable martensite transformed to ferrite, and so did some of the retained austenite; the amount of ferrite and austenite continued rising after 1 or 2 $\mathrm{h}$ of tempering. The increase in hardness after tempering at $300{ }^{\circ} \mathrm{C} / 3 \mathrm{~h}$ is likely to be related to the transformation of residual austenite into martensite (during cooling) and some precipitation of transitional carbides. After 4 hours, more carbon left the ferrite and austenite, reducing their volume fractions, and precipitated as cementite. The enthalpy of process II, according to the DSC analysis presented in Fig 11, was the highest for ribbons (Table 2), suggesting that the transformation of austenite into ferrite, as well as the precipitation effect were the most intensified. The hardness obtained at $350{ }^{\circ} \mathrm{C} / 2 \mathrm{~h}$ was very similar to the one at $300{ }^{\circ} \mathrm{C} / 3 \mathrm{~h}$ indicating, that a lower temperature requires longer times to achieve a similar diffusion behaviour of carbon. For all other samples, the hardness decreased with increasing tempering temperature. When comparing the enthalpy of the second effect in all samples, it can be seen that the carbide free bainitic SB steel revealed the lowest value, suggesting that it either had the lowest amount of austenite or that it was more thermodynamically stable.

During heating in the range of $437-530^{\circ} \mathrm{C}\left(\mathrm{III}^{\mathrm{rd}}\right.$ positive effect), cementite precipitation most likely occurred. In the SB steel with a carbide free bainitic structure (obtained through the standard heat treatment), continuous heating showed that austenite decomposed in the range of $450-600{ }^{\circ} \mathrm{C}$. When the content of $\mathrm{Si}$ is increased up to $3.8 \mathrm{wt} \%$, the decomposition temperature of austenite could be as high as $600{ }^{\circ} \mathrm{C}$ [23]. However, the precipitation of cementite in $100 \mathrm{Cr} 6$ thixo-cast during tempering occurred at $470^{\circ} \mathrm{C}$ due to a lower Si content [24]. In the present study, a typical cast microstructure with segregation of elements into a eutectic phase was observed. The inhomogeneous distribution of mainly $\mathrm{C}, \mathrm{Si}$, and $\mathrm{Mn}$ led to 
a different phase transformation than in the conventionally treated SB steel. The IV ${ }^{\text {th }}$ effect, which appeared only in ribbons is most likely related to the recrystallisation of the structure.

\section{Conclusions}

1. Melt spun steel ribbons of a chemical composition normally designed to generate nanostructured bainite showed a typical cellular microstructure with a cell size of about 0.5 $\mu \mathrm{m}$. The cells contained untempered martensite and retained austenite. Each cell was surrounded by a three-dimensional network of cementite, giving the whole structure a microhardness of $963 \pm 42 \mathrm{HV}$.

2. Plates of the same steel, obtained using suction-injection, had a lower hardness of $778 \mathrm{HV}$ due to a lower cooling rate, which affected the size and distribution of phases in comparison with the melt spun ribbons. The structure of the plates consisted of relatively coarse dendrites (20-80 $\mu \mathrm{m})$ made of a mixture of austenite and martensite with cementite in between. Their coarser length scale relative to the melt spun material was a consequence of the lower cooling rates associated with the suction-injection process.

3. Thixoforming of the same steel from the semi-solid state led to a hardness in the range 410$610 \mathrm{HV}$, the higher values originating from the $70 \%$ of particles which were unmelted at $1430^{\circ} \mathrm{C}$ (temperature at which $30 \%$ liquid exists). The lower hardness of $410 \mathrm{HV}$ is due to secondary ferrite grains of an average size of about $20 \mu \mathrm{m}$ and a eutectic mixture that formed from the liquid phase.

4. Tempering at 150,250 , and $350{ }^{\circ} \mathrm{C} / 2 \mathrm{~h}$ led to a decrease in hardness with increasing temperature in all samples except for the ribbons, in which hardness increased after tempering at $300-350{ }^{\circ} \mathrm{C} / 2 \mathrm{~h}$, due to the transformation of austenite into carbon rich ferrite and the precipitation of transitional carbides. Further tempering brought about a decrease in hardness due to microstructure coarsening and the formation of $\mathrm{M}_{3} \mathrm{C}$ carbides.

\section{Acknowledgments.}

The research was supported by Polish science financial resources Applied Research Programme of the National Centre for Research and Development in Poland; "Developing a technology of producing complex elements by steel thixoforming” PBS1/B5/22/2013.

\section{References}


[1] G. Hirt, R. Kopp, 'Thixoforming, Semi-Solid Metal Processing', 1-52, 2009, Verlag Wiley-Vch.

[2] M.C. Flemings, 'Behavior of metal alloys in the semisolid state', Metall. Mater. Trans. A, 1991, 22A, 957-981.

[3] J. Hufenbach, S. Kohlar, U. Kühn, L. Giebeler, J. Eckert, 'The effect of boron on microstructure and mechanical properties of high-strength cast FeCrVC', J. Mat. Sci., 2012, 47/1, 267-271.

[4] K. I Sugimoto, T. Muramatsu, S. I. Hashimoto, Y. Mukai, 'Formability of Nb bearing ultra high-strength TRIP-aided sheet steels', J Mater Process Technol., 2006, 177-390.

[5] K. Mori, K. Akita, Y. Abe, 'Springback behaviour in bending of ultra-high-strength steel sheets using CNC servo press', Int J Mach Tools Manuf., 2007, 47-321.

[6] W. Kurz, D. J. Fisher, 'Fundamentals of Solidification', 1986, Verlag, Trans Tech Publications.

[7] E. Karakose and M. Keskin, 'Effect of solidification rate on the microstructure and microhardness of a melt-spun Al-8Si-1Sb alloys', J.Alloys Comp., 2009, 479, 230-236.

[8] E.J. Pickering, H.K.D.H. Bhadeshia, 'Macrosegregation and Microstructural Evolution in a Pressure-Vessel Steel', Metall. Mater. Trans. A, 2014, 45A, 2983-2997. [9] F. G. Caballero, H. K. D. H Bhadeshia, 'Very strong bainite'. Current Opinion in Solid State and Materials Science, 2004, 8/3, 251-257.

[10] H. K. D. H. Bhadeshia, 'The first bulk nanostructured metal'. Sci. Technol. Adv. Mater. $2013,14 / 1,1-7$.

[11] W. Solano-Alvarez and H. K. D. H. Bhadeshia, 'White-etching matter in bearing steel. Part II: distinguishing cause and effect in bearing steel failure', Metall. Mater. Trans. A, 2014, 45/11, 4916-4931.

[12] D. J. Dyson and B. Holmes, 'Effect of alloying additions on the lattice parameter of austenite', J Iron Steel I, 1970, 208, 469-474.

[13] E. Honda and Z. Nishiyama, 'On the nature of the tetragonal and cubic martensites', Science Reports of Tohoku Imperial University, 1932, 21, 299-331.

[14] A. Inoue, Z. Tao, 'Fabrication of bulky Zr-based glassy alloys by suction casting into copper mold'. Materials Transactions. JIM 1995, 36, 1184-1187

[15] A. Inoue, T. Zhang, E. Makabe, 'Production methods of metallic glasses by a suction casting method', US 5740854 A, 1998

[16] A.G. Gillen, B. Cantor, 'Photocalorimetric cooling rate measurements on a Ni-5wt\%Al alloy rapidly solidified by melt-spinning', Acta Metall. 1985, 33, 1813-1825.

[17] V. Sumsal, V. Vodarek, P. Kawulok, 'Progressive Steels Used For Centrifugally Cast Rolls', Progresívní Oceli Používané Pro Odstředivě Lité Válce, Conference Metal 2010, Roznov pod Radhostem, Ceska Republika.

[18] S. Chatterjee, H. K. D. H. Bhadeshia, 'TRIP-assisted steels: cracking of high carbon martensite', Mater. Sci. Technol., 2006, 22/6, 645-649.

[19] F. G. Caballero, C. Garcia-Mateo, M. K. Miller, 'Design of Novel Bainitic. Steels: Moving from Ultra Fine to Nanoscale Structures', JOM, 2014, vol. 66, pp. 747-755.

[20] F.G. Caballero, H.K.D.H. Bhadeshia, K.J.A. Mawella, D.G. Jones, P. Brown, 'Very Strong Low Temperature Bainite', Mater. Sci. Technol., 2002, 18, 279-284.

[21] Saha Podder an H. K. D. H. Bhadeshia, 'Thermal stability of austenite retained in bainitic steels', Mater. Sci. Eng. A, 2010, 527/7-8, 2121-2128.

[22] http://www.icdd.com/products/pdf2.htm

[23] C. N. Hulme-Smith, I. Lonardelli, A.C. Dippel, H. K. D. H. Bhadeshia,'Enhanced Thermal Stability in Nanostructured Bainitic Steel', Scripta Mater. 2013, 69/55, 409-412.

[24] Ł Rogal, J Dutkiewicz, 'Effect of annealing on microstructure, phase composition and mechanical properties of thixo-cast 100Cr6 steel', Mater. Charact., 2012, 68, 123-130. 
[25] Ł. Rogal, W. Solano-Alvarez, Z. Szklarz, and H. K. D. H. Bhadeshia. "Feasibility study for thixoforming nanostructured bainitic steels." Materials Science and Engineering: A 651 (2016): 708-719.

\section{Figure Captions:}

Figure 1. Cast samples a) ribbons using melt spinning methods, b) plates with run cast obtained using suction casting, c) thixo-formed elements obtained by rapid quenching from the solidus-liquidus temperature range.

Figure 2. DSC data during heating steel sample at $20^{\circ} \mathrm{C} / \mathrm{s}$

Figure 3. SEM microstructures of ribbon a) cross-section, b) in direct contact with $\mathrm{Cu}$ wheel and c) $15 \mu \mathrm{m}$ below the-surface of contact.

Figure 4. TEM image of the surface of the ribbon in contact with the $\mathrm{Cu}$-wheel with carbide skeleton marked with arrows.

Figure 5. a) TEM bright field image of superbainitic steel ribbons along with diffraction data from: b) cementite, c) grains within the network.

Figure 6. Bright field TEM image of SB steel ribbon with diffraction data showing twins of martensite.

Figure 7. X-ray diffraction spectra of SB steel samples after a) melt spinning, b) thixoforming, and c) suction casting. The dots refer to $\mathrm{M}_{3} \mathrm{C}$ peaks whose volume percentage was not possible to accurately determine.

Figure 8. Microstructure of rapidly quenched SB steel into copper die, a) optical microstructure observed with Nomarski contrast and nital etching, b) SEM image of grains surrounded by a secondary phase with numerous casting defects, and c) TEM bright field image with annotated carbide and martensite phases.

Figure 9. Microstructure of thixo-formed superbainitic steel, etched in Nital, obtained using a) optical microscopy, and b) SEM image.

Figure 10. a) SEM micrograph of SB steel thixo-formed (with line scan and points of analysis) and b) line scan of composition changes of characteristic radiation of $\mathrm{Fe} \mathrm{K} \alpha, \mathrm{C} \mathrm{K} \alpha$, $\mathrm{Mn} \mathrm{K} \alpha$, Si K $\alpha$, and Mo K $\alpha$. 
Figure 11. Heating flow curves obtained using DSC analysis of the SB steel in the form of plate, thixo-formed material, ribbon (directly after casting), and SB steel under standard heat treatment $\left(1000^{\circ} \mathrm{C} / 15 \mathrm{~min}\right.$ followed by $\left.240{ }^{\circ} \mathrm{C} / 5 \mathrm{~h}\right)$.

Figure 12 . Hardness vs tempering at $150-550{ }^{\circ} \mathrm{C} / 2 \mathrm{~h}$ of SB steel directly after casting: ribbons, plate, thixo-formed material, and SB steel under standard heat treatment $\left(1000^{\circ} \mathrm{C} / 15 \mathrm{~min}\right.$ followed by $240^{\circ} \mathrm{C} / 5 \mathrm{~h}$ ).

Figure 13. Bright field TEM microstructure of as-cast steel ribbons after tempering at 350 ${ }^{\circ} \mathrm{C} / 2 \mathrm{~h}$ and electron diffraction pattern of the area.

Figure 14. SB steel ribbons after tempering at $350{ }^{\circ} \mathrm{C} / 2 \mathrm{~h}$ : a) HRTEM image of the microstructure with an insert of Fast Fourier Transform, b) Fourier filtered image showing (111) lattice fringes - with marked dislocations and magnified area with the lattice distances and their mutual angles measured.

Figure 15. Filtered Inverse image FFT obtained for chosen reflections a) 002, b) 011, c) 110 .

Figure 16. Hardness (HV0.5) of as-cast steel ribbons after tempering at $300{ }^{\circ} \mathrm{C}$ for $1,2,3$, and 4 hs.

\section{Table captions}

Table 1. Results of EDS analysis of thixo-formed superbainitic steel.

Table 2. Thermal effect and enthalpy of phase transformation obtained during continuous heating of SB steel plate, ribbon, thixo-formed material, and SB steel under standard heat treatment.

Table 3. X-ray analysis results after Rietveld refinement for the superbainitic steel in the form of thixo-formed material, plate, and ribbon all tempered at $350^{\circ} \mathrm{C} / 2 \mathrm{~h}$.

Table 4. X-ray analysis results after Rietveld refinement for the superbainitic steel ribbons in the as-cast state and tempered at $300{ }^{\circ} \mathrm{C}$ for 1 and $4 \mathrm{~h}$. 